\title{
Properties of acid gels made from sodium caseinate-maltodextrin conjugates prepared by a wet heating method
}

\author{
Shuwen Zhang, ${ }^{*} †$ Yuansheng Gong, $†$ Som Khanal, $†$ Yanjie Lu, $\ddagger$ and John A. Lucey* $\ddagger^{1}$ \\ *Department of Food Science, University of Wisconsin, Madison 53706 \\ †Institute of Food Science and Technology, Chinese Academy of Agricultural Sciences, Beijing 100193, China \\ $\ddagger$ Center for Dairy Research, University of Wisconsin, Madison 53706
}

\section{ABSTRACT}

Covalent attachment of polysaccharides to proteins (conjugation) via the Maillard reaction has been extensively studied. Conjugation can lead to a significant improvement in protein functionality (e.g., solubility, emulsification, and heat stability). Caseins have previously been successfully conjugated with maltodextrin $(\mathrm{Md})$, but the effect on the detailed acid gelation properties has not been examined. We studied the effect of conjugating sodium caseinate $(\mathrm{NaCN})$ with 3 different sized Md samples via the Maillard reaction in aqueous solutions. The Md samples had dextrose equivalents of 4 to 7,9 to 12 , and 20 to 23 for Md40, Md100, and Md200, respectively. The conjugation reaction was performed in mixtures with $5 \% \mathrm{NaCN}$ and $5 \% \mathrm{Md}$, which were heated at $90^{\circ} \mathrm{C}$ for $10 \mathrm{~h}$. The degree of conjugation was estimated from the reduction in free amino groups as well as color changes. Sodium dodecyl sulfate-PAGE analysis was performed to confirm conjugation by employing staining of both protein and carbohydrate bands. The molar mass of samples was determined by size-exclusion chromatography coupled with multiangle laser light scattering. After the conjugation reaction, samples were then gelled by the addition of $0.63 \%$ (wt/vol) glucono- $\delta$-lactone at $30^{\circ} \mathrm{C}$, such that samples reached $\mathrm{pH} 4.6$ after about $13 \mathrm{~h}$. The rheological properties of samples during acidification was monitored by small-strain dynamic oscillatory rheology. The microstructure of acid gels at $\mathrm{pH} 4.6$ was examined by fluorescence microscopy. Conjugation resulted in a loss of $10.8,8.8$, and $11.9 \%$ of the available amino groups in the protein for the $\mathrm{NaCN}-\mathrm{Md} 40$ conjugates (C40), NaCN-Md100 conjugates (C100), and NaCN-Md100 conjugates (C200), respectively. With a decrease in the size of the type of $\mathrm{Md}$, an increase occurred in the molar mass of the resultant conjugate. The weight average molar masses of NaCN-Md samples were 340,

Received January 16, 2017.

Accepted July 20, 2017.

${ }^{1}$ Corresponding author: jlucey@cdr.wisc.edu
368 , and $425 \mathrm{kDa}$ for the conjugates $\mathrm{C} 40, \mathrm{C} 100$, and $\mathrm{C} 200$, respectively. Addition of $\mathrm{Md}$ to $\mathrm{NaCN}$ dispersion resulted in slightly shorter acid gelation times even without the conjugation reaction. The storage modulus $\left(G^{\prime}\right)$ of acid gels was significantly lower in conjugated samples compared with the corresponding (unreacted) mixtures of $\mathrm{Md}$ and $\mathrm{NaCN}$. The sample with the lowest $\mathrm{G}^{\prime}$ value at $\mathrm{pH} 4.6$ was the $\mathrm{C} 40$ conjugate. Fluorescence microscopy showed that gels made by conjugates had slightly larger pores. These results indicate that conjugation of casein modified its acid gelation properties, presumably by the Md polysaccharide moiety hindering aggregation and rearrangements of the casein network. Key words: sodium caseinate-maltodextrin conjugate, rheological property, acid milk gel

\section{INTRODUCTION}

Sodium caseinate $(\mathbf{N a C N})$ is extensively used in food industry as a functional ingredient in a wide variety of products due to its versatile functional properties, including solubility, heat stability, foaming, and emulsifying capacities (Dalgleish, 1997; Dickinson, 2003). Maltodextrin (Md) powders are widely used in the food industry as stabilizers (texture and bulking modifiers), for example, in food emulsions (Loret et al., 2004), or as an aid in spray drying. Maltodextrin is a hydrolysis product of starch consisting of $\alpha-(1,4)$ and $\alpha-(1,6)$ linked D-glucose polymers, oligomers, or both, with dextrose equivalent (DE) values less than 20. Maltodextrin is a complex mixtures of high and low molecular weight materials, Md samples with low DE values retain longer oligosaccharide chains (Kasapis et al., 1993).

In recent years there has been significant research interest in altering protein functionality through conjugation with reducing sugars or polysaccharides (Oliver et al., 2006; Liu et al., 2012; O'Mahony et al., 2016). This conjugation process is usually performed by heating and exploiting the Maillard reaction. The covalent attachment of sugars to proteins can modify the surface charge, molar mass, and other physical or functional 
properties of this new protein-carbohydrate conjugate. The conjugation of whey proteins has been extensively studied (Fenaille et al., 2003; Jiménez-Castaño et al., 2005; Zhu et al., 2010; Sun et al., 2011; Wang and Ismail, 2012; Spotti et al., 2014).

Conjugation of $\mathrm{Md}$ to $\mathrm{NaCN}$ via the Maillard reaction leads to significant improvement in the functional properties of the caseins (Shepherd et al., 2000). Shepherd et al. (2000) reported that casein-maltodextrin conjugates had excellent emulsifying properties. O'Regan and Mulvihill (2009) showed that NaCN-Md conjugates had improved solubility compared with $\mathrm{NaCN}$, particularly in environments around the isoelectric point of the protein. Conjugation also resulted in increase in casein solubility and foaming ability (Grigorovich et al., 2012). Hiller and Lorenzen (2011) reported that yogurt made by fortification of milk with $\mathrm{NaCN}$, which had previously undergone conjugation, had little effect on gel strength or whey drainage. Hiller and Lorenzen (2011) did not report on the dynamic rheological properties or microstructure of these gels. Corzo-Martínez et al. (2010) studied the effect of the Maillard reaction on the rheological properties of $\mathrm{NaCN}$. After $\mathrm{NaCN}$ was conjugated with galactose and lactose, the viscosity of the conjugates was higher than the non-conjugated $\mathrm{NaCN}$. It was suggested that conjugation affected the rheological properties of conjugates due to casein aggregation and covalent crosslinking (Corzo-Martínez et al., 2010). The DE value of Md likely affects its functional properties because the DE value is inversely related to the degree of polymerization of the molecule (Dokic-Baucal et al., 2004).

The majority of these conjugation studies were conducted under dry-heating conditions to promote the reaction between protein and carbohydrate (Shepherd et al., 2000; O'Regan and Mulvihill, 2009; Morris et al., 2004; Grigorovich et al., 2012). However, the dry-heating method takes a long time to complete the reaction and is not favorable for industrial application. Zhu et al. (2008) developed an alternative wet-heating method for this conjugation reaction. In this wet-heating method, the reaction is done in a liquid environment but with very high concentrations of polysaccharides, which act as a macromolecular crowding agent hindering protein unfolding during the heat treatment (Zhu et al., 2008).

Rheological behavior is associated with functional properties of food proteins, such as foaming properties, gelling capacity, and also affects the textural qualities of food, for example, mouth feel, taste, and shelf-life stability (Herh et al., 2000). Acidification of $\mathrm{NaCN}$ with glucono- $\delta$-lactone (GDL) has been used to prepare model casein gels (Lucey et al., 1997a,b). Acidification of milk reduces the charge on caseins, dissolving some of the insoluble calcium phosphate crosslinks and modifying internal bonding between caseins (Lucey, 2016). Gelation occurs at some critical point when electrostatic repulsion is reduced and is not sufficient to overcome attractive forces like hydrophobic interactions (Lucey, 2016). Acid gels made with $\mathrm{NaCN}$ are a simpler model milk protein system due to the absence of insoluble calcium phosphate as well as the lack of a micellar structure.

In this study, we studied the conjugation reaction between $\mathrm{NaCN}$ and $\mathrm{Md}$ with different molecular weight in aqueous solutions via the wet-heating method. The rheological properties and microstructure of acidinduced gels made from $\mathrm{NaCN}-\mathrm{Md}$ conjugates were investigated.

\section{MATERIALS AND METHODS}

\section{Materials}

Sodium caseinate (protein content $\sim 90 \%$ ) was obtained from Kerry Ingredients (Beloit, WI). The maltodextrins, Maltrin40 (Md40), Maltrin100 (Md100), and Maltrin200 (Md200) with DE values of 4-7, 9-12, and 20-23, respectively, were obtained from Grain Processing Corporation (Muscatine, IA). The GDL (Sigma-Aldrich, St. Louis, MO) was used as an acidogen. All other chemicals were of analytical grade (Sigma-Aldrich).

\section{Preparation of the NaCN-Md Conjugates}

The $\mathrm{NaCN}$ and $\mathrm{Md}$ (i.e., the Md40, Md100, and Md200) were individually dissolved in Milli-Q water at $10 \%$ (wt/vol), equal volumes of the aqueous solutions were mixed together, and final concentrations of maltodextrin and sodium caseinate in the mixture were $5 \%$. The sample solutions were stirred on a magnetic stirrer at room temperature $\left(\sim 22^{\circ} \mathrm{C}\right)$ for $2 \mathrm{~h}$ to completely dissolve the mixture. Sodium azide $\left(\mathrm{NaN}_{3}, 0.02 \%\right.$ wt/wt) was added to prevent bacterial growth in these samples. Aliquots of the solutions were placed in a water bath heated at $90^{\circ} \mathrm{C}$ for $10 \mathrm{~h}$. Samples were then taken out of the water bath and immediately cooled in an ice bath. Triplicates were performed for each experiment.

\section{Determination of Extent of Conjugation}

Determination of Available Amino Groups. The degree of conjugation was estimated using a colorimetric assay to determine the change in free amino groups. The concentration of available amino groups in $\mathrm{NaCN}, \mathrm{NaCN}-\mathrm{Md}$ mixtures, and conjugates were determined by the trinitrobenzene sulfonate method as 
described by Habeeb (1966) and O'Regan and Mulvihill (2009).

Color Measurements. The color changes as a result of conjugation was determined by measuring the Hunter chromaticity coordinates $\left(\mathrm{L}^{*}, \mathrm{a}^{*}, \mathrm{~b}^{*}\right)$ with a Colorflex CX2706 (Hunter Associates Laboratory Inc., Reston, VA). The instrument was calibrated with a standard white tile $(\mathrm{X}=80.86, \mathrm{Y}=85.68$, and $\mathrm{Z}=89.76)$ before measurement. The NaCN, NaCN-Md mixtures, or conjugate samples were placed into a Petri dish and the $L^{*}, a^{*}$, and $b^{*}$ color coordinates were measured. In the $\mathrm{L}^{*}, \mathrm{a}^{*}$, and $\mathrm{b}^{*}$ color space system, $\mathrm{L}^{*}$ values quantify lightness/darkness, whereas positive $a^{*}$ values indicate redness, negative $a^{*}$ values indicate greenness, positive $b^{*}$ values indicate yellowness, and negative $b^{*}$ values indicate blueness (Francis and Clydesdale, 1975; O'Regan and Mulvihill, 2009).

$\boldsymbol{S D S}-\boldsymbol{P A G E}$. The SDS-PAGE was performed on a Mini-Protean 3 Cell (Bio-Rad Laboratories, Hercules, CA) according to the method of Laemmli (1970). Reducing SDS-PAGE analyses were performed on precast gels (Tris- $\mathrm{HCl}$ gel, 4-20\% linear gradient, 12 wells, Bio-Rad Laboratories). Solutions of NaCN, NaCN-Md mixtures, or conjugates $(1 \%$, wt/vol, protein, based on protein concentration of the dried materials) were prepared in sample buffer and heated at $95^{\circ} \mathrm{C}$ for $3 \mathrm{~min}$ before loading in the each well. Electrophoresis was run for $35 \mathrm{~min}$ at $200 \mathrm{~V}$ in a $1 \times$ Tris- $\mathrm{HCl}$ buffer solution at room temperature $\left(\sim 22^{\circ} \mathrm{C}\right)$. After electrophoresis, one gel was stained for protein by Coomassie blue G-250 and the other one was stained for carbohydrate by the GelCode Glycoprotein staining kit (Pierce Biotechnology).

Size Exclusion Chromatography Coupled with Multi-Angle Laser Light Scattering. Determination of the molar mass of conjugates was performed by size exclusion chromatography coupled with multiangle laser light scattering (SEC-MALLS; Zhu et al., 2010). Samples were diluted 50 -fold in sample buffer (20 m $M$ imidazole, $50 \mathrm{~m} M \mathrm{NaCl}, 0.1 \% \mathrm{NaN}_{3}$, pH 7.0). The sample solution was filtered through a $0.45 \mu \mathrm{m}$ filter before injection into the SEC column. The NaCN$\mathrm{Md}$ mixtures and conjugates (1\%) were applied to a SEC-MALLS system, using Superose 6HR 10/30 and Superose 12HR 10/30 columns (Amersham Pharmacia Biotech AB, Uppsala, Sweden) arranged in series, at a flow rate of $0.3 \mathrm{~mL} / \mathrm{min}$. The $\mathrm{SEC}$ was connected to a Waters 600 HPLC system. Sample injection volume was $100 \mu \mathrm{L}$. Ten millimolar phosphate buffer was used as an eluent. Elution from columns was monitored at $280 \mathrm{~nm}$ with a photodiode array detector (model 996, Waters Corp., Milford, MA) and a differential refractive index detector (model 2410, Waters Corp.) and a MALLS photometer (DAWN EOS, Wyatt Technology,
Santa Barbara, CA; fitted with a helium-neon laser $\lambda$ $=690 \mathrm{~nm}$, and K5-flow cell). A value of $0.19 \mathrm{~mL} / \mathrm{g}$ was used for the refractive index increment (dn/dc; Lucey et al., 2000). Data collected by the photodiode array, differential refractive index detectors, and MALLS photometer were processed by the software ASTRA (version 4.73 04, Wyatt Technology) to calculate the weight-average molar mass $(\mathbf{M w})$ of the conjugate according to the method of Lucey et al. (2000). The SEC-MALLS measurements were carried out at $\sim 22^{\circ} \mathrm{C}$.

\section{Acidification and Gelation Properties}

The NaCN, the NaCN-Md mixtures, and conjugates solutions were acidified with GDL at $0.63 \%$ (wt/vol). This GDL level resulted in $\mathrm{NaCN}$ solutions having $\mathrm{pH}$ values of approximately 4.6 after $13 \mathrm{~h}$ at $30^{\circ} \mathrm{C}$. A model PCM 700 Orion Sensor Link system (Orion Research Inc., Beverly, MA), connected to a computer, was used to continuously monitor $\mathrm{pH}$ changes during acidification. $\mathrm{pH}$ measurements were taken every 2 min during acidification.

Rheological Properties. Gel formation was monitored by small-strain dynamic rheology using the Physica MCR 301 (Anton Paar, Graz, Austria) rheometer as described by Lucey et al. (1997a). The parameters measured included the storage modulus $\left(\mathbf{G}^{\prime}\right)$ and loss tangent (LT). A profiled cup and bob measuring geometry was used. The cup and bob measuring geometry consisted of 2 coaxial cylinders (inner diameter 25 $\mathrm{mm}$; outer diameter $27.5 \mathrm{~mm}$ ). On addition of GDL to solutions, the mixture was stirred vigorously for approximately $2 \mathrm{~min}$ before $17 \mathrm{~mL}$ of the mixture were transferred to the rheometer. To prevent evaporation, gels were covered with vegetable oil. Gels were oscillated at a frequency of $0.1 \mathrm{~Hz}$ and measurements were taken every 2 min at $30^{\circ} \mathrm{C}$ until pH of 4.6 was reached. Gelation was defined as the point when the $\mathrm{G}^{\prime}$ value of gels was greater than $1 \mathrm{~Pa}$ (Lucey et al., 1997a). The large deformation properties of gels formed in situ were determined by applying a single, constant shear rate $\left(0.01 \mathrm{~s}^{-1}\right)$ up to the yielding of gel. The deformation strain for the small-amplitude oscillation was $1 \%$. Yield stress was defined as the point when shear stress started to decrease. Yield strain was the strain value at the yield point (Lucey et al., 1997a).

Microstructure. The microstructure of gels was examined at $\mathrm{pH} 4.6$ using the fluorescence microscopy method of Choi et al. (2007). Twenty-five milliliters of samples were mixed with $150 \mu \mathrm{L}$ of acridine orange ( $0.2 \%$ wt/wt; Sigma Chemical Co.). After stirring, a few drops of the mixture were transferred to slides with a cavity, and a coverslip was placed over the sample. The slides were placed in a temperature-controlled in- 
cubator (model 650F, Fisher Scientific, Hanover, IL) and incubated at $30^{\circ} \mathrm{C}$ until the $\mathrm{pH}$ was $\sim 4.6$. Microstructure of gels samples was viewed with a fluorescence microscope (Axioskop 2 plus, Carl Zeiss, Eching, Germany). Deconvolution was used to remove out-offocus material (Choi et al., 2007). Triplicate slides were prepared and randomly selected fields that were typical for each slide were reported.

\section{RESULTS AND DISCUSSION}

\section{Conjugate Characterization}

The covalent bond formation for conjugation mainly occurs between the $\varepsilon$-amino group of lysine residues in proteins and carbonyl group of reducing carbohydrates (Oliver et al., 2006). In this study, the degree of conjugation of the $\mathrm{NaCN}-\mathrm{Md}$ product was estimated by measuring the reduction in free amino groups. Conjugation resulted in a loss of $10.8,8.8$, and $11.8 \%$ of the available amino groups in the protein for the NaCN-Md40 conjugates (C40), NaCN-Md100 conjugates (C100), and NaCN-Md100 conjugates (C200), respectively (Table 1). O'Regan and Mulvihill (2010) reported that reaction of $\mathrm{NaCN}$ and Md100 resulted in a loss of $\sim 36 \%$ of available amino groups; however, they conducted their conjugation reaction by the more intense dry heating method where samples were freeze-dried and then heated at $60^{\circ} \mathrm{C}$ and $79 \%$ relative humidity for $96 \mathrm{~h}$.

Moderate browning was observed following conjugation indicating the formation of some intermediate or advanced Maillard reaction products (Table 1). Conjugation resulted in a decrease in $\mathrm{L}^{*}$ and a decrease in $\mathrm{a}^{*}$ and $\mathrm{b}^{*}$, in agreement with previous studies (O'Regan and Mulvihill, 2009, 2010). Browning color increased with decreasing molecular weight of Md. Thus, C40 had lighter color compared with $\mathrm{C} 100$ and C200. This behavior might be explained considering that the smaller the size of the polysaccharide, the less would be the steric hindrance, and the easier it would likely be for the initial conjugate to progress through the Maillard reaction to intermediate or advanced stages that involve the creation of colored (brown) compounds (Zhu et al., 2008). Previous research has shown that the removal of low molecular weight sugars from Md by membrane dialysis prior helped to significantly reduce the brown/ yellow color that could develop during conjugation with NaCN (Shepherd et al., 2000; O'Regan and Mulvihill, 2009); dialysis probably also reduced the extent of conjugation as smaller sugars conjugate easier than larger polysaccharides.

The SDS-PAGE was performed to confirm conjugation and to also estimate the approximate molecular weight of the conjugates. The SDS-PAGE gel, stained for protein with Coomassie brilliant blue R-250, and stained for polysaccharide with periodic acid/fuchsin reagent, are shown in Figure 1. Typical monomeric caseins were observed in the $\mathrm{NaCN}$ and $\mathrm{NaCN}-\mathrm{Md}$ mixtures (Figure 1a; lanes 1, 3, 6, and 9). The individual casein bands partly disappeared on conjugation, with a distinct shift to a broad range of high molecular weight conjugated proteins (Figure 1a; lanes 4, 7, and 10). However, not all of the individual casein bands completely disappeared in the conjugate, indicating that the reaction between the $\mathrm{NaCN}$ and $\mathrm{Md}$ had not gone to completion. A portion of the conjugate sample also remained in the loading wells of the gel, which suggested the presence of very high molecular weight conjugated protein that was too large to enter the separating gel (Figure 1a, lanes 4, 7, and 10). Similar results were previously reported (Shepherd et al., 2000; O'Regan and Mulvihill, 2009).

Table 1. The loss of available amino groups in the sodium caseinate $(\mathrm{NaCN})$ as a result of conjugation with maltodextrin $(\mathrm{Md})$ and the effect of heating at $90^{\circ} \mathrm{C}$ for $10 \mathrm{~h}$ on the color $\left(\mathrm{L}^{*}, \mathrm{a}^{*}, \mathrm{~b}^{*}\right)$ of these NaCN-Md conjugates $^{1}$

\begin{tabular}{lccrr}
\hline Item $^{2}$ & Loss of available amino groups (\%) & L* & $\mathrm{a}^{*}$ & $\mathrm{~b}^{*}$ \\
\hline $\mathrm{NaCN}$ & 0 & $56.18 \pm 0.36$ & $-1.02 \pm 0.08$ & $5.26 \pm 0.13$ \\
$\mathrm{Md} 40$ & - & $63.06 \pm 0.45$ & $-0.39 \pm 0.04$ & $2.31 \pm 0.24$ \\
Md100 & - & $65.38 \pm 0.52$ & $-0.72 \pm 0.03$ & $1.18 \pm 0.08$ \\
Md200 & $65.34 \pm 0.38$ & $-0.70 \pm 0.05$ & $1.15 \pm 0.03$ \\
M40 & Not measured & $55.92 \pm 0.34$ & $-1.19 \pm 0.06$ & $5.00 \pm 0.11$ \\
C40 & $10.8 \pm 0.2$ & $44.66 \pm 0.46$ & $12.94 \pm 0.14$ & $15.77 \pm 0.22$ \\
M100 & Not measured & $55.09 \pm 0.38$ & $-0.58 \pm 0.05$ & $6.56 \pm 0.19$ \\
C100 & $8.8 \pm 0.5$ & $41.33 \pm 0.37$ & $14.18 \pm 0.09$ & $19.89 \pm 0.16$ \\
M200 & Not measured & $55.29 \pm 0.32$ & $-0.70 \pm 0.07$ & $6.65 \pm 0.17$ \\
C200 & $11.9 \pm 0.5$ & $38.12 \pm 0.27$ & $14.15 \pm 0.06$ & $21.63 \pm 0.24$ \\
\hline
\end{tabular}

${ }^{1} \mathrm{~L}^{*}=$ lightness; $\mathrm{a}^{*}=$ redness; $\mathrm{b}^{*}=$ yellowness.

${ }^{2} \mathrm{NaCN}$ was assumed to represent $100 \%$ available amino groups. Md40, Md100, Md200 = Maltrin40, Maltrin100, Maltrin200, respectively (Grain Processing Corporation, Muscatine, IA); M40 $=$ NaCN-Md40 mixture; C40 $=\mathrm{NaCN}-\mathrm{Md} 40$ conjugate; M100 $=$ NaCN-Md100 mixture; C100 $=$ NaCN-Md100 conjugate; M200 = NaCNMd200 mixture; C200 = NaCN-Md200 conjugate. Values are the means of triplicates. 
The Md present in the NaCN-Md conjugates (Figure $1 \mathrm{~b}$, lanes 4,7 , and 10) migrated through the gel with the protein as indicated by the formation of smeared bands with molecular weights ranging from about 30 to $>200$ $\mathrm{kDa}$. Some Md remained near the top of the separating gels for all the samples containing $\mathrm{Md}$, as indicated by the strong color. The presence of these bands as well as the corresponding protein bands observed for those molecular weight ranges for the protein stained gel (Figure 1a) confirmed that conjugation had occurred and that
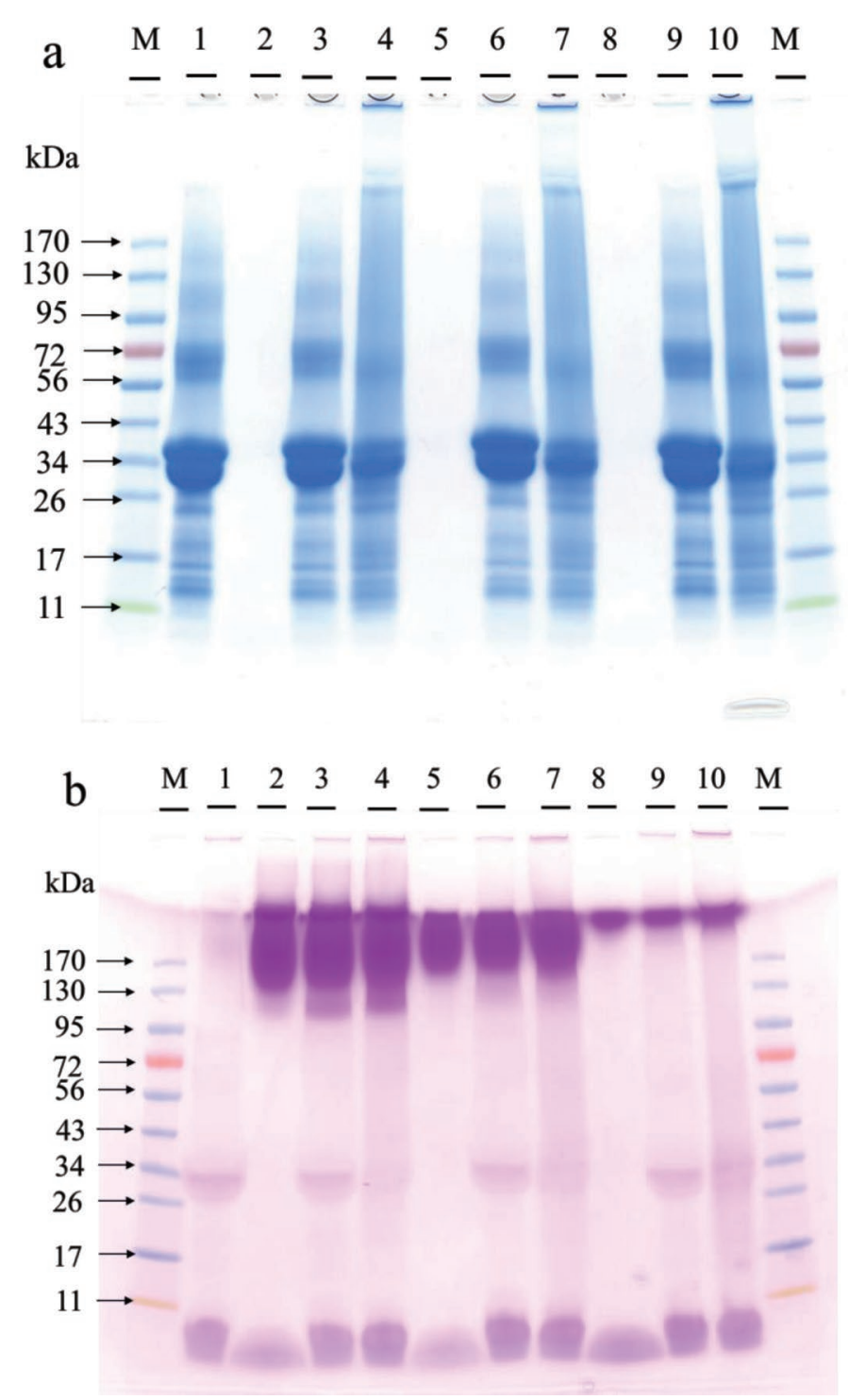

Figure 1. Sodium dodecyl sulfate-PAGE stained for protein with Coomassie brilliant blue R-250 (a) and stained for carbohydrate with periodic acid/fuschin reagent (b). The labeled lanes are (M) molecular weight marker, (1) sodium caseinate $(\mathrm{NaCN}),(2)$ maltrodextrin $(\mathrm{Md})$ 40, (3) mixture of $\mathrm{NaCN}$ and $\mathrm{Md} 40$, (4) conjugate of NaCN-Md40, (5) Md100, (6) mixture of $\mathrm{NaCN}$ and Md100, (7) conjugate of NaCNMd100, (8) Md200, (9) mixture of $\mathrm{NaCN}$ and Md200, and (10) conjugate of NaCN-Md200. Color version available online. the Md was covalently attached to the $\mathrm{NaCN}$. Covalent linkage formation upon conjugation of $\mathrm{NaCN}-\mathrm{Md}$ has previously been confirmed by SDS-PAGE (Shepherd et al., 2000; O'Regan and Mulvihill, 2009, 2010). Conjugation of $\mathrm{NaCN}$ with $\mathrm{Md}$ has previously been reported to create higher molecular weight bands using the SDSPAGE technique (Shepherd et al., 2000; O'Regan and Mulvihill, 2009, 2010; Cardoso et al., 2011).

The SEC-MALLS elution profiles (not shown) were similar to those previously reported for $\mathrm{NaCN}$ with 2 main peaks at around 25 to 30 and 35 to $40 \mathrm{~mL}$ (Lucey et al., 2000). The elution profile between 18 and $40 \mathrm{~mL}$ was used for determination of the $\mathrm{Mw}$ value. The Mw for $\mathrm{NaCN}$ and for Md40, Md100, and Md200 samples was $88,60,18$, and $9 \mathrm{kDa}$, respectively (results not shown), as determined by SEC-MALLS. The Mw values were 312,353 , and $288 \mathrm{kDa}$ for the M40, M100, and M200 samples, respectively. The Mw was 340, 368, and $425 \mathrm{kDa}$ for the $\mathrm{C} 40, \mathrm{C} 100$, and C200 samples, respectively. Only a small change occurred in the $\mathrm{Mw}$ of conjugate samples with the use of larger sized Md (i.e., Md with DE values of 4-7 and 9-12, Md40 and Md100, respectively). Conjugation with the smaller sized $\mathrm{Md}$ (i.e., Md with DE value of 20-23, Md 200) resulted in a large increase in the $\mathrm{Mw}$ of conjugate. This increase in the $\mathrm{Mw}$ of $\mathrm{NaCN}$ after conjugation with $\mathrm{Md}$ can be seen in the cumulative molar mass distribution curves (Figure 2). Some low Mw material $\left(<1 \times 10^{4} \mathrm{~g} / \mathrm{mol}\right)$ was observed in the cumulative molar mass profiles for the M200 sample (Figure 2c), presumably reflecting the contribution from small sized Md because this sample had a DE value of 20 to 23. A larger shift occurred in the cumulative molar mass distribution profile after conjugation for the M200 sample (Figure 2c), suggested that the lower molecular weight Md samples (higher $\mathrm{DE}$ value) were more easily conjugated with caseinate molecules than higher molecular weight Md (e.g., Figure 2a). Because the $\mathrm{Md}$ to $\mathrm{NaCN}$ molar ratio varied in our experiments, this could help explain the more intense reaction with the Md200 sample. O'Regan and Mulvihill (2009) performed SEC on their C40 and C100 conjugates and observed broader peaks as well as an increase in molar mass after conjugation. However, the SEC method used by O'Regan and Mulvihill (2009) did not determine the actual molar mass of conjugates.

\section{Properties of Acid Gels}

The changes in $\mathrm{pH}$ as a function of time for the various samples are shown in Figure 3. During acidification, there was a rapid initial decrease in $\mathrm{pH}$ but after $200 \mathrm{~min}$ the rate of decrease in $\mathrm{pH}$ slowed. Acid gels made with $\mathrm{NaCN}$, NaCN-Md mixtures, and $\mathrm{NaCN}-\mathrm{Md}$ conjugates had similar $\mathrm{pH}$ profiles. Acid gels made with 
NaCN-Md conjugates had slightly $(P<0.05)$ lower gelation $\mathrm{pH}$ comparing to gels made with $\mathrm{NaCN}$ or mixture of $\mathrm{NaCN}$ and $\mathrm{Md}$ (Table 2). This was probably because of the blockage of lysine due to the Maillard reaction induced a slight loss of basicity, which led to a noticeable shift of the isoelectric point of glycated proteins toward more acidic pH (Fenaille et al., 2003).

Morris et al. (2004) also reported that conjugation of $\mathrm{NaCN}$ with $\mathrm{Md}$ resulted in an increase in mass-to-
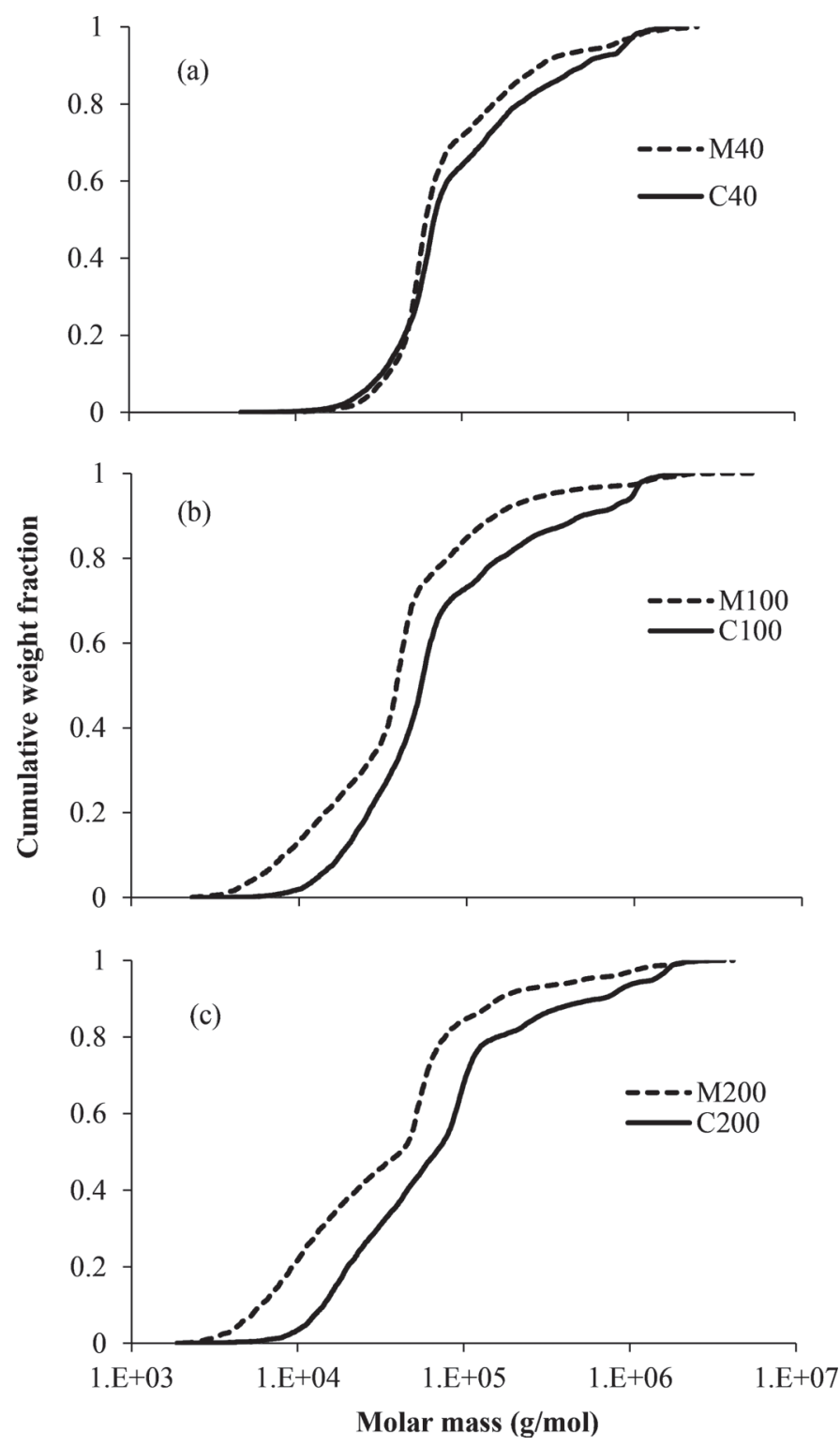

Figure 2. Cumulative molar mass distribution during size exclusion chromatography coupled with multi-angle laser light scattering for (a) mixture of $\mathrm{NaCN}$ and maltrodextrin 40 (M40), conjugate sample for $\mathrm{NaCN}$ and maltrodextrin 40 (C40); (b) mixture of $\mathrm{NaCN}$ and maltrodextrin 100 (M100), conjugate sample for $\mathrm{NaCN}$ and maltrodextrin 100 (C100); and (c) mixture of $\mathrm{NaCN}$ and maltrodextrin 200 (M200), conjugate sample for $\mathrm{NaCN}$ and maltrodextrin 200 (C200).

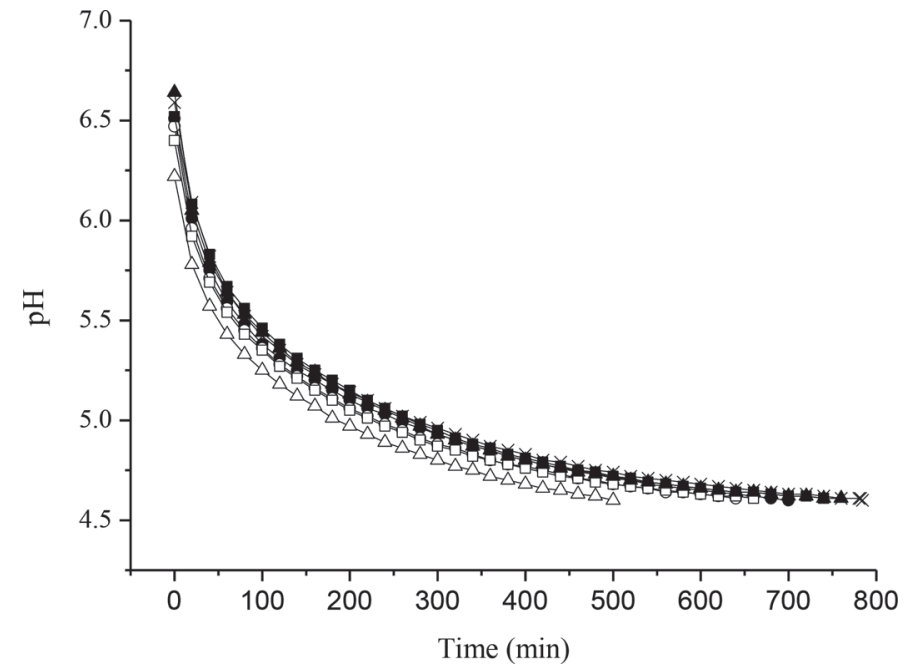

Figure 3. pH profiles as a function of time for acid gels made by sodium caseinate $(\mathrm{NaCN} ; \times)$, mixture of $\mathrm{NaCN}$ and maltodextrin $(\mathrm{Md}) 40(\mathbf{)})$, conjugate sample of $\mathrm{NaCN}$ and Md40 (O), mixture of $\mathrm{NaCN}$ and Md100 (ם), conjugate sample of NaCN and Md100 ( $\square$ ), mixture of $\mathrm{NaCN}$ and $\mathrm{Md} 200(\mathbf{\Delta})$, and conjugate sample of $\mathrm{NaCN}$ and $\operatorname{Md} 200(\Delta)$. Gels were made at $30^{\circ} \mathrm{C}$ with glucono- $\delta$-lactone. Data are means of triplicates.

charge ratio of the materials. There was also a significant difference $(P<0.05)$ in the time to $\mathrm{pH} 4.6$ for the various types of acid gels (Table 2). Conjugation resulted in faster gelation compared with gels made with only $\mathrm{NaCN}$, possibly due to the loss of titratable (amino) groups on protein with conjugation formation.

The $\mathrm{G}^{\prime}$ values and LT profiles of acid gels as a function of time are shown in Figure 4. A summary of the rheological properties is given in Table 2. Conjugation had a significant effect on $\mathrm{G}^{\prime}$ values at $\mathrm{pH} 4.6(P<0.05$; Table 2). Conjugation resulted in a marked decrease in $\mathrm{G}^{\prime}$ values of gels compared with mixtures and $\mathrm{NaCN}$ gels (Figure 4a). With the increase in the $\mathrm{Mw}$ of $\mathrm{Md}$, the $\mathrm{G}^{\prime}$ values of acid gels made from the corresponding conjugates decreased. Furthermore, conjugation resulted in a decrease in yield stress (Figure 5; Table 2).

Previous studies (Liu et al., 2012) indicated that conjugation of whey protein affected thermal denaturation and aggregation behavior. Rich and Foegeding (2000) reported that conjugation of whey protein isolates (WPI) with lactose decreased the fracture stress of heat-induced whey protein gels, whereas ribose conjugation to WPI increased gel elasticity. Spotti et al. (2014) reported that conjugation significantly modified the rheological behavior of WPI-dextran (DX) systems and that gels made by conjugates was weaker than mixed systems. Sun et al. (2011) studied WPI conjugated to a DX $(150 \mathrm{kDa})$ by oscillatory rheology and found that the $\mathrm{G}^{\prime}$ values of WPI/DX conjugate systems were much lower than gels from WPI alone. The different results 
Table 2. Summary of rheological properties of acid gels made with mixtures of sodium caseinate (NaCN) and maltodextrin (Md) as well as from NaCN-Md conjugates $(\mathrm{C})^{1}$

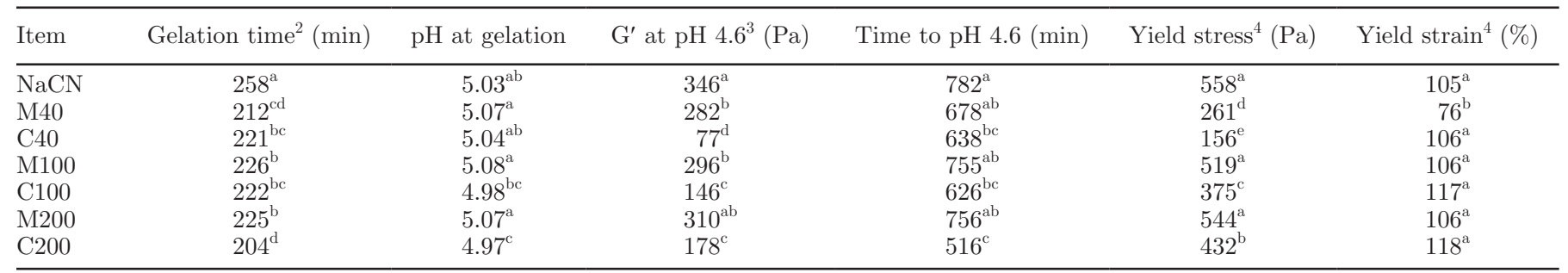

${ }^{\mathrm{a} e}$ Values with different letters within the same column were significantly different $(P<0.05)$.

${ }^{1}$ Values are the means of triplicates. Md40, Md100, Md200 = Maltrin40, Maltrin100, Maltrin200, respectively (Grain Processing Corporation, Muscatine, IA); M40 = NaCN-Md40 mixture; C40 = NaCN-Md40 conjugate; M100 = NaCN-Md100 mixture; C100 = NaCN-Md100 conjugate; M200 $=$ NaCN-Md200 mixture; C200 = NaCN-Md200 conjugate.

${ }^{2}$ Gelation time was defined as the point when gels had a storage modulus $\geq 1 \mathrm{~Pa}$.

${ }^{3} \mathrm{G}^{\prime}=$ storage modulus.

${ }^{4}$ These properties were determined when the $\mathrm{pH}$ of yogurt gels reached 4.6.

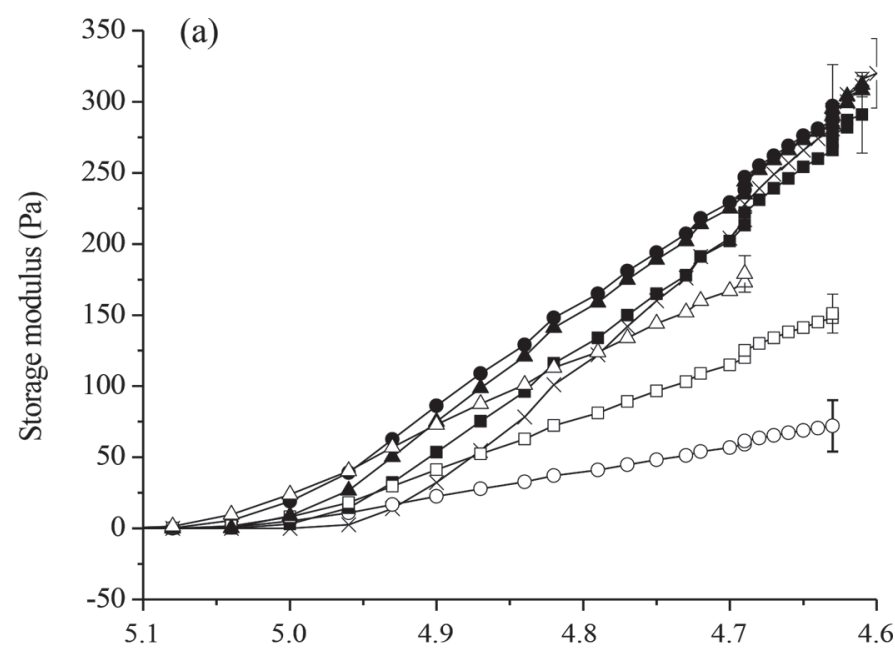

reported for whey protein gels presumably reflect the effect of some sugars helping to stabilize WPI from denaturation, which would increase the time and temperature required for gelation, whereas other sugars/ polysaccharides may promote covalent cross-linking of the proteins (Rich and Foegeding, 2000). Studies on the thermal gelation properties of egg white protein also indicated that conjugation with some types of reducing sugars could improve gel properties (Sun et al., 2004).

The development of gel strength in casein gels needs protein-protein aggregation and fusion, as well as rearrangements (Lucey, 2002). However, the covalent attachment of Md to caseinate molecules could sterically
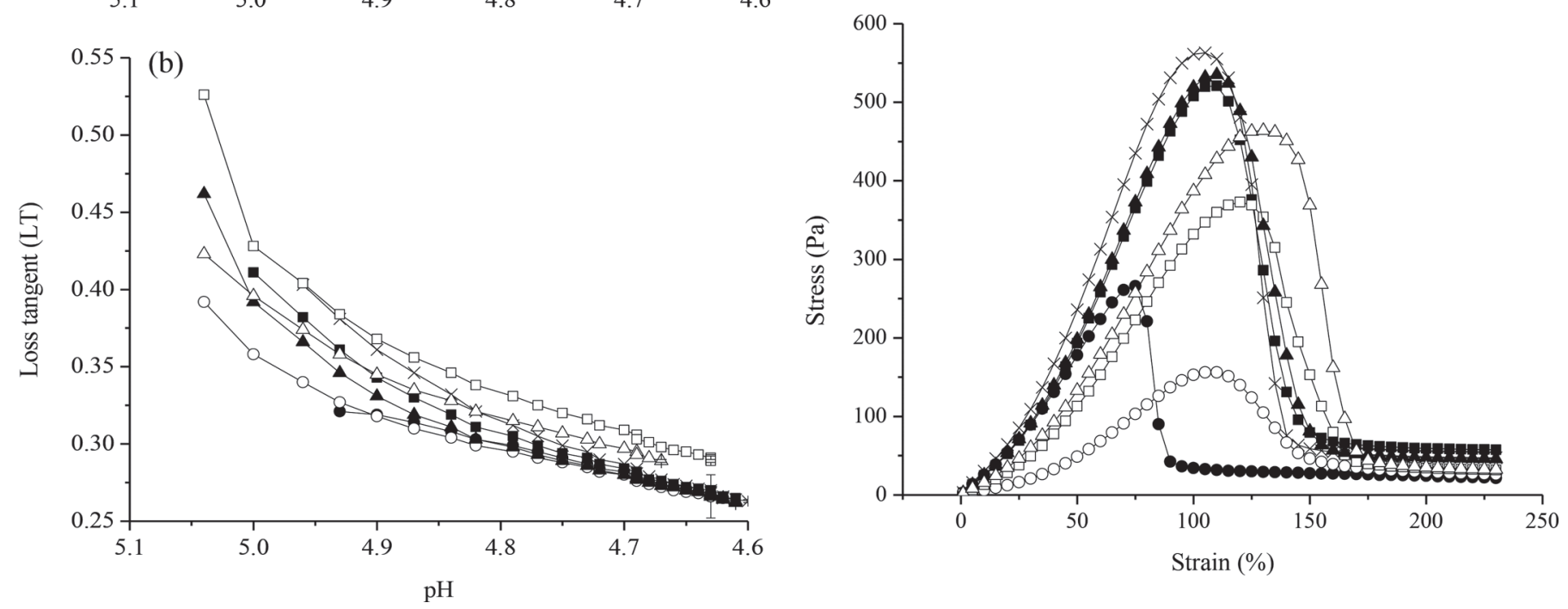

Figure 4. Storage modulus $\left(\mathrm{G}^{\prime} ; \mathrm{a}\right)$ and loss tangent $(\mathrm{LT} ; \mathrm{b})$ as a function of $\mathrm{pH}$ for acid gels made at $30^{\circ} \mathrm{C}$ with glucono- $\delta$-lactone. Gels made by sodium caseinate $(\mathrm{NaCN} ; \times)$, mixture of $\mathrm{NaCN}$ and maltodextrin (Md) $40(\bullet)$, conjugate sample of $\mathrm{NaCN}$ and Md40 (○), mixture of $\mathrm{NaCN}$ and Md100 (ם), conjugate sample of $\mathrm{NaCN}$ and Md100 $(\square)$, mixture of $\mathrm{NaCN}$ and $\mathrm{Md} 200(\mathbf{\Lambda})$, and conjugate sample of $\mathrm{NaCN}$ and $\operatorname{Md} 200(\Delta)$. Data are means of triplicates.

Figure 5. Shear stress as a function of strain for shearing at a constant shear rate $\left(0.01\right.$ per second) for acid gels made at $30^{\circ} \mathrm{C}$ with glucono- $\delta$-lactone. Gels made by sodium caseinate $(\mathrm{NaCN} ; \times)$, mixture of $\mathrm{NaCN}$ and maltodextrin $(\mathrm{Md}) 40(\bullet)$, conjugate sample of $\mathrm{NaCN}$ and $\mathrm{Md} 40(\mathrm{O})$, mixture of $\mathrm{NaCN}$ and $\mathrm{Md} 100(\mathbf{\square})$, conjugate

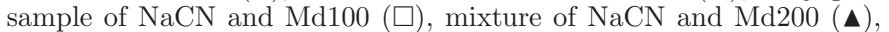
and conjugate sample of $\mathrm{NaCN}$ and $\operatorname{Md} 200(\Delta)$. Data are means of triplicates. 

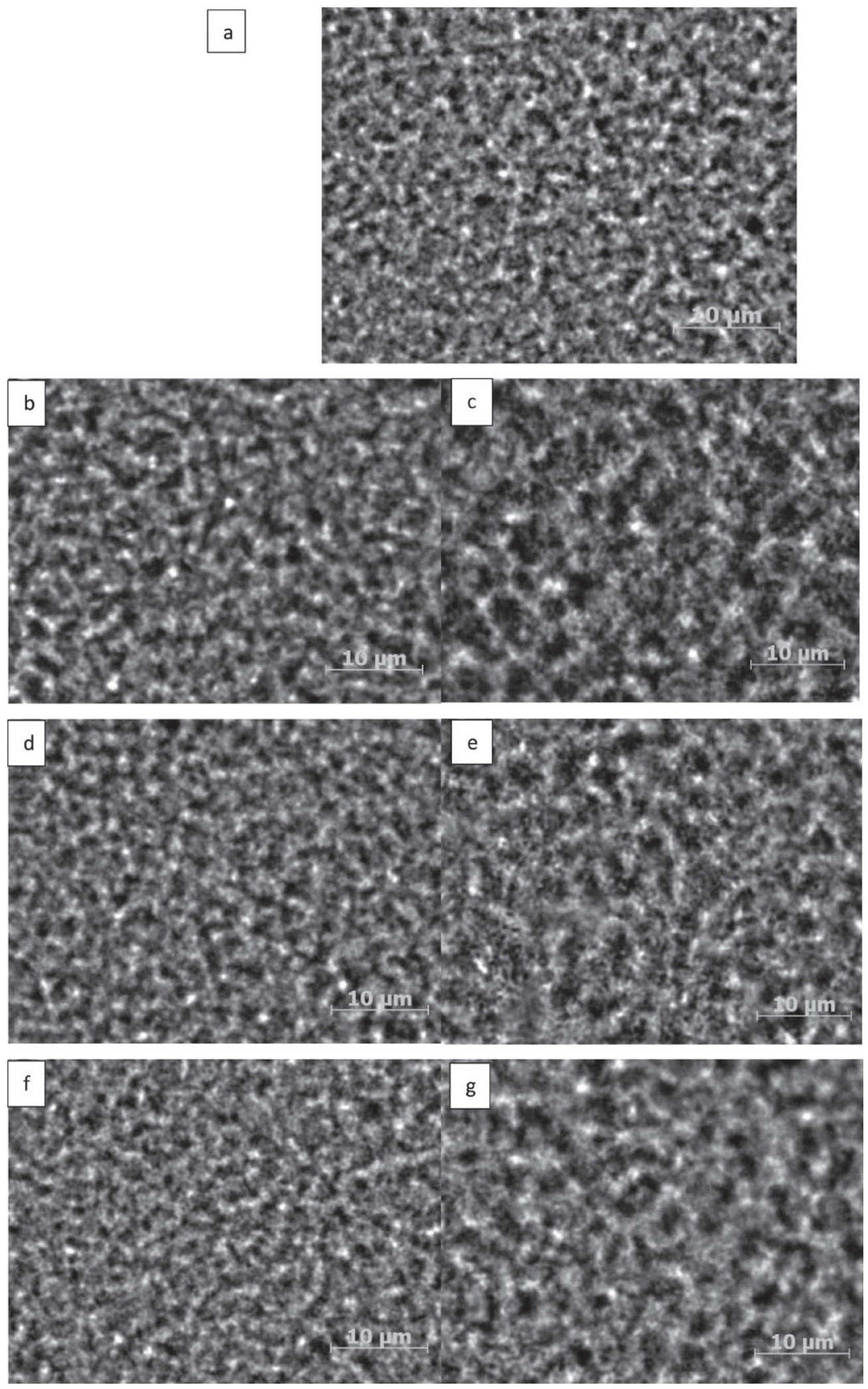

Figure 6. Microstructure of acid gels made at $30^{\circ} \mathrm{C}$ with glucono- $\delta$-lactone. Gels made by sodium caseinate (NaCN) (a), mixture of NaCN and maltodextrin (Md) 40 (b), conjugate sample of NaCN and Md40 (c), mixture of NaCN and Md100 (d), conjugate sample of NaCN and Md100 (e), mixture of $\mathrm{NaCN}$ and $\mathrm{Md} 200$ (f), and conjugate sample of $\mathrm{NaCN}$ and $\mathrm{Md} 200$ (g). The protein matrix is white and pores are dark; scale bar $=10 \mu \mathrm{m}$. 
inhibit the fusion of caseinate particles thus reducing final gel strength. Rearrangements of casein gels is critical to the ongoing increase in gel stiffness with aging time (Van Vliet et al., 1997). Steric hindrance to casein rearrangement (ongoing fusion) by the attachment of larger sized Md molecules to caseinate molecules could explain why there was a greater reduction in the $\mathrm{G}^{\prime}$ and yield stress values of conjugate gels with an increase in the molecular weight of the type of Md. Mixtures of $\mathrm{NaCN}$ and $\mathrm{Md}$ had significantly higher $\mathrm{G}^{\prime}$ values at $\mathrm{pH} 4.6$ than the corresponding $\mathrm{NaCN}-\mathrm{Md}$ conjugates (Table 2). Thus, it appears that covalent attachment of Md to caseinate molecules alters the aggregation/rearrangements of caseins much more than just the mere presence of (soluble) $\mathrm{Md}$ in $\mathrm{NaCN}$ gel systems. The attachment of a hydrophilic moiety to casein particles could also reduce hydrophobic interactions between caseins that likely play a role in acid gel development.

The LT values decreased gradually after gelation, similar results were previously observed by Lucey et al. (1997a) for the acid-induced gelation of NaCN. No maximum in LT was observed during acidification in contrast to the profiles for milk (Lucey, 2016), which is likely because NaCN has no insoluble calcium phosphate and has a low $\mathrm{pH}$ of gelation. The maximum in LT observed in acid milk gels is a consequence of a partial loosening of the weak initial gel network due to the solubilization of insoluble calcium phosphate, whereas at lower $\mathrm{pH}$ values there would be increased proteinprotein attractions between casein particles as the net charge decreases with the approach of the isoelectric point (Lucey, 2016). Slightly higher LT profiles during acidification were observed in acid gels made with conjugate samples C100 and C200 compared with other samples (Figure 4b), possibly due to the attachment of Md causing more flexibility and mobility within the casein network.

The microstructures of acid gel made from NaCN, $\mathrm{NaCN}-\mathrm{Md}$ mixture, and $\mathrm{NaCN}-\mathrm{Md}$ conjugates are shown in Figure 6. Gels made from $\mathrm{NaCN}$ and $\mathrm{NaCN}$ Md mixtures appeared to have small pores and more interconnections between strands. Gels made with C40 had very large pores, weak gels, and very little interconnectivity in agreement with their low $\mathrm{G}^{\prime}$ values at pH 4.6 (Table 1).

\section{CONCLUSIONS}

Conjugation of $\mathrm{NaCN}$ with Md significantly affected the rheological properties of acid gels. Conjugation resulted in lower storage modulus and yield stress values of acid gels compared with gel made with only $\mathrm{NaCN}$ or mixtures of $\mathrm{NaCN}$ and $\mathrm{Md}$. The molecular weight of the Md affected acid gelation, with weaker gels created with larger molecular weight Md samples. We conclude that the covalently attached Md sterically hindered the aggregation and fusion of caseinate particles that are needed for the creation of stiff gel structures. Although conjugation of caseinate with Md has previously been shown to improve some functional properties (such as solubility and emulsification), it appeared to negatively affect acid gelation properties.

\section{ACKNOWLEDGMENTS}

The financial support of the Wisconsin Center for Dairy Research (Madison) is greatly appreciated.

\section{REFERENCES}

Cardoso, J. C., R. L. C. Albuquerque Jr., F. F. Padilha, F. O. Bittencourt, O. De Freitas, P. S. Nunes, N. L. Pereira, M. J. V. Fonseca, and A. A. S. Araújo. 2011. Effect of the Maillard reaction on properties of casein and casein films. J. Therm. Anal. Calorim. 104:249-254.

Choi, J., D. S. Horne, and J. A. Lucey. 2007. Effect of insoluble calcium concentration on rennet coagulation properties of milk. J. Dairy Sci. 90:2612-2623.

Corzo-Martínez, M., F. J. Moreno, M. Villamiel, and F. M. Harte. 2010. Characterization and improvement of rheological properties of sodium caseinate glycated with galactose, lactose and dextran. Food Hydrocoll. 24:88-97.

Dalgleish, D. G. 1997. Structure-function relationship of caseins. Pages 199-223 in Food Proteins and Their Applications. S. Damodaran and A. Paraf, ed. Marcel Dekker Inc., New York, NY.

Dickinson, E. 2003. Interfacial, emulsifying and foaming properties of milk proteins. Pages 1229-1260 in Advanced Dairy Chemistry, vol. 1: Proteins, 3rd ed. P. F. Fox and P. L. H. McSweeney, ed. Kluwer Academic/Plenum Publishers, Dordrecht, the Netherlands.

Dokic-Baucal, L., P. Dokic, and J. Jakovljevic. 2004. Influence of different maltodextrins on properties of $\mathrm{O} / \mathrm{W}$ emulsions. Food Hydrocoll. 18:233-239.

Fenaille, F., F. Morgan, V. Parisod, J. C. Tabet, and P. A. Guy. 2003. Solid-state glycation of $\beta$-lactoglobulin monitored by electrospray ionisation mass spectrometry and gel electrophoresis techniques. Rapid Commun. Mass Spectrom. 17:1483-1492.

Francis, F. J., and F. M. Clydesdale. 1975. Food Colorimetry: Theory and Applications. Avi Publishing Co. Inc., Westport, CT.

Grigorovich, N. V., D. V. Moiseenko, A. S. Antipova, M. S. Anokhina, L. E. Belyakova, Y. N. Polikarpov, N. Korica, M. G. Semenova, and B. A. Baranov. 2012. Structural and thermodynamic features of covalent conjugates of sodium caseinate with maltodextrins underlying their functionality. Food Funct. 3:283-289.

Habeeb, A. F. 1966. Determination of free amino groups in proteins by trinitrobenzenesulfonic acid. Anal. Biochem. 14:328-336.

Herh, P. K., S. M. Colo, N. Roye, and K. Hedman. 2000. Rheology of foods: New techniques, capabilities, and instruments. Am. Lab. $32: 16-20$.

Hiller, B., and P. C. Lorenzen. 2011. Properties of set-style skim milk yoghurt as affected by an enzymatic or Maillard reaction induced milk protein oligomerisation. LWT Food Sci. Technol. 44:811-819.

Jiménez-Castaño, L., R. López-Fandiño, A. Olano, and M. Villamiel. 2005. Study on $\beta$-lactoglobulin glycosylation with dextran: Effect on solubility and heat stability. Food Chem. 93:689-695.

Kasapis, S., E. R. Morris, I. T. Norton, and A. H. Clark. 1993. Phase equilibria and gelation in gelatine/maltodextrin system-Part I: Gelation of individual components. Carbohydr. Polym. 21:243-259. 
Laemmli, U. K. 1970. Cleavage of structural proteins during the assembly of the head of bacteriophage T4. Nature 227:680-685.

Liu, J., Q. Ru, and Y. Ding. 2012. Glycation a promising method for food protein modification: Physicochemical properties and structure, a review. Food Res. Int. 49:170-183.

Loret, C., V. Meunier, W. J. Frith, and P. J. Fryer. 2004. Rheological characterisation of the gelation behaviour of maltodextrin aqueous solutions. Carbohydr. Polym. 57:153-163.

Lucey, J. A. 2002. Formation and physical properties of milk protein gels. J. Dairy Sci. 85:281-294.

Lucey, J. A. 2016. Acid coagulation of milk. Pages 309-328 in Advanced Dairy Chemistry, Volume 2, Proteins. 4rd edn. P. L. H. McSweeney, and J.A. O'Mahony, ed. Kluwer Publishers, New York, NY.

Lucey, J. A., M. Srinivasan, H. Singh, and P. A. Munro. 2000. Characterization of commercial and experimental sodium caseinates by multiangle laser light scattering and size-exclusion chromatography. J. Agric. Food Chem. 48:1610-1616.

Lucey, J. A., T. Van Vliet, K. Grolle, T. Geurts, and P. Walstra. 1997a. Properties of acid casein gels made by acidification with glucono- $\delta$ lactone. 1. Rheological properties. Int. Dairy J. 7:381-388.

Lucey, J. A.. T. Van Vliet, K. Grolle, T. Geurts, and P. Walstra 1997b. Properties of acid casein gels made by acidification with glucono- $\delta$-lactone. 2. Syneresis, permeability and microstructural properties. Int. Dairy J. 7:389-397.

Morris, G. A., I. M. Sims, A. J. Robertson, and R. H. Furneaux. 2004. Investigation into the physical and chemical properties of sodium caseinate-maltodextrin glyco-conjugates. Food Hydrocoll. 18:1007-1014.

O'Mahony, J. A., K. P. Drapala, E. M. Mulcahy, and D. M. Mulvihill. 2016. Controlled glycation of milk proteins and peptides: Functional properties. Int. Dairy J. 67:16-34.

O'Regan, J., and D. M. Mulvihill. 2009. Preparation, characterisation and selected functional properties of sodium caseinate-maltodextrin conjugates. Food Chem. 115:1257-1267.

O'Regan, J., and D. M. Mulvihill. 2010. Heat stability and freeze-thaw stability of oil-in-water emulsions stabilized by sodium caseinatemaltodextrin conjugates. Food Chem. 119:182-190.
Oliver, C. M., L. D. Melton, and R. A. Stanley. 2006. Creating proteins with novel functionality via the Maillard reaction: A review. Crit. Rev. Food Sci. Nutr. 46:337-350.

Rich, L. M., and E. A. Foegeding. 2000. Effect of sugars on whey protein isolate gelation. J. Agric. Food Chem. 48:5046-5052.

Shepherd, R., A. Robertson, and D. Ofman. 2000. Dairy glycoconjugate emulsifiers: casein-maltodextrins. Food Hydrocoll. 14:281286

Spotti, M. J., M. J. Martinez, A. M. Pilosof, M. Candioti, A. C. Rubiolo, and C. R. Carrara. 2014. Rheological properties of whey protein and dextran conjugates at different reaction times. Food Hydrocoll. 38:76-84.

Sun, W. W., S. J. Yu, X. Q. Yang, J. M. Wang, J. B. Zhang, Y. Zhang, and E. L. Zheng. 2011. Study on the rheological properties of heatinduced whey protein isolate-dextran conjugate gel. Food Res. Int. 44:3259-3263.

Sun, Y., S. Hayakawa, and K. Izumori. 2004. Antioxidative activity and gelling rheological properties of dried egg white glycated with a rare keto-hexose through the Maillard reaction. J. Food Sci. 69:427-434.

Van Vliet, T., J. A. Lucey, K. Grolle, and P. Walstra. 1997. Rearrangements in acid-induced casein gels during and after gel formation. Pages 335-345 in Food Colloids, Proteins, Lipids and Polysaccharides. Royal Society of Chemistry, Cambridge, UK.

Wang, Q., and B. Ismail. 2012. Effect of Maillard-induced glycosylation on the nutritional quality, solubility, thermal stability and molecular configuration of whey protein. Int. Dairy J. 25:112-122.

Zhu, D., S. Damodaran, and J. A. Lucey. 2008. Formation of whey protein isolate (WPI) - dextran conjugates in aqueous solutions. J. Agric. Food Chem. 56:7113-7118.

Zhu, D., S. Damodaran, and J. A. Lucey. 2010. Physicochemical and emulsifying properties of whey protein isolate (WPI)-dextran conjugates produced in aqueous solution. J. Agric. Food Chem. 58:2988-2994. 